RU Концепт «мужество» в поэме К. М. Симонова «Сын артиллериста» Чжан Вэй

\begin{abstract}
Аннотация. Цель исследования - описание одного из важнейших художественных концептов поэзии К. М. Симонова военных лет - концепта «мужество», репрезентирующего нравственно-этическую концепцию жизни и смерти в произведении «Сын артиллериста». Новизна исследования заключается в выбранном автором подходе к анализу произведения, в предпринятой попытке выявить индивидуально-авторское наполнение концепта «мужество» в «Сыне артиллериста». Полученные результаты показали, что концепт «мужество» организует концептуальное пространство произведения, будучи аксиологической доминантой художественного мира автора. Различные ипостаси мужества, воплощенные в судьбах героев, образуют его идеал, соотнесенный с «константами народного сознания»; через систему оппозиций расставляются знаковые для поэта акценты. Концепт «мужества» воплощается прежде всего как нравственный императив: мужество есть внутренняя потребность, сформированная высокими представлениями о чести и долге, преданности, верности, служении народу, самопожертвовании.
\end{abstract}

\title{
Concept “Courage” in K. M. Simonov’s Poem “The Artilleryman’s Son”
}

\author{
Zhang Wei
}

\begin{abstract}
The purpose of the study is to describe one of the most important literary concepts of K. M. Simonov's wartime poetry - the concept "courage" representing the moral and ethical conceptual idea of life and death in the work "The Artilleryman's Son". Scientific novelty of the study lies in the researcher's approach to analysing the work, in an attempt to identify the individual author's content of the concept "courage" in "The Artilleryman's Son". The attained results have shown that the concept "courage" organises conceptual space of the work, being axiological dominant of the author's literary world. Various manifestations of courage embodied in the characters' fates form its ideal correlated with "constants of national consciousness"; points pivotal to the poet are emphasised through the system of oppositions. The concept "courage" is realised primarily as a moral imperative: courage is an internal need formed by high ideas of honour and duty, devotion, loyalty, service to the people, self-sacrifice.
\end{abstract}

\section{Введение}

Поэзия военного времени - уникальная глава в истории русской литературы. В ней в афористически сжатом и эмоционально сконцентрированном виде воплотились глубинные идеи русского национального сознания, базовые для русской культуры концепты. Произведения, созданные в трагические годы Великой Отечественной войны, «надежнее памятников тому времени, отлитых в бронзе или высеченных из камня, сохраняют в себе общенациональные чувства и переживания» [5, с. 29]. Этим и объясняется интерес к изучению концептосферы поэзии периода Великой Отечественной войны, пробудившийся в последнее время [2; 8]. Актуальность заявленной темы обусловлена тем, что в литературоведении пока еще нет монографических работ, посвященных изучению художественной реализации когнитивно-семантического потенциала поэзии Великой Отечественной войны. Опираясь на материалы отдельных исследований концептов в творчестве поэтов военного времени и привлекая данные словарей и статьи по смежной тематике, мы обнаружили непреложный факт: в концептосфере советской поэзии периода Великой Отечественной войны одним из важнейших концептов является концепт «мужество». Становясь аксиологической доминантой в произведениях, посвященных суровым военным испытаниям, он воплощается в них и в ассоциативно-образной системе, и в мотивных комплексах, и во всех других составляющих художественного текста. Сама идея мужества сопрягается с «главными для русской культуры смысловыми константами: идеей сопричастности человека к судьбе страны, стремлением к добру и красоте, тягой к справедливости» [4, с. 112].

В задачи исследования входили проведение комплексного анализа текста поэмы К. М. Симонова «Сын артиллериста», выявление особенностей смыслового наполнения и средств реализации в ней художественного

Научная статья (original research article) । https://doi.org/10.30853/phil210425

(๔) 2021 Авторы. 000 Издательство «Грамота» (๔ 2021 The Authors. GRAMOTA Publishers). Открытый доступ предоставляется на условиях лицензии СС ВY 4.0 (open access article under the CС BY 4.0 license): https://creativecommons.org/licenses/by/4.0/ 
концепта «мужество», установление его роли в концептосфере поэмы, определение значимости данного концепта в художественном мире автора.

В работе использовались социокультурный метод, а также методы целостного и концептуального анализа.

Теоретическую базу исследования составляют работы в области когнитивного литературоведения, посвященные описанию специфики художественных концептов и особенностям их репрезентации в поэтическом творчестве $[1 ; 2 ; 4 ; 8]$ и др., работы по истории русской литературы, в том числе посвященные изучению творчества К. М. Симонова [3; 6; 7] и др.

Практическая значимость работы: материалы исследования могут способствовать дальнейшему изучению индивидуально-авторской концептосферы К. М. Симонова, а также концептосферы поэтических произведений периода Великой Отечественной войны в целом; полученные результаты могут быть использованы в вузовских и школьных курсах по истории русской литературы.

\section{Мужество как аксиологическая доминанта творчества К. М. Симонова}

Концепт «мужество», будучи базовым концептом большинства культур, имеет как общенациональные, так и национально-специфические компоненты, которые обусловливаются особенностями историко-культурного развития нации, формирующимися на протяжении всего ее исторического пути. Как один из важнейших в концептосфере произведений военной тематики, концепт «мужество» оказывается неразрывно связанным с концептом «война», который, в частности в песенном дискурсе, как указывает Е. И. Голованова, реализуется через символические образы, «прецедентные в рамках русской культуры», огня, дыма, пожарищ, через образ родной земли, которую нужно защитить, спасти, пусть даже ценою жизни [4, с. 113].

Представления о мужестве запечатлеваются в пословицах, поговорках, фразеологизмах, а также в афористическом, прежде всего литературном по происхождению фонде. В творчестве К. М. Симонова, многие строки которого относятся к золотому фонду афоризмов, концепт «мужество» воплощается в императивном ключе, причем эта императивность неразрывно связана с потребностями времени, с задачей «укрепить силу духа тех, кто сражался на фронте против захватчиков и самозабвенно работал для фронта в тылу, приблизить победу. Определивший весь строй жизни народа лозунг “Все для фронта, все для победы!” распространялся и на искусство» [10, с. 9].

Главной во всем, что пишет К. М. Симонов о войне, становится, по словам К. А. Роговой, «тема беззаветного подвига, преданности и верности... Эта тема и это убеждение, как считают исследователи его творчества, были порождением, с одной стороны, того воспитания, которое Симонов получил в семье - военного, дворянина, превыше всего почитающего долг служения Родине, с другой - верности советским идеалам, сформированной уже в сознательном возрасте» [9, с. 119]. Совершенно очевидно, что представления поэта о мужестве, тесно связанном с подвигом и с преданностью, и с верностью, корнями уходят вглубь семейно-родовой и национально-культурной традиции.

Обращаясь к предвоенной лирике К. М. Симонова, заметим, что идеал мужества определяется веком, заработавшим «суровое право» быть мужественным, это «привычка сражаться, / Острое фронтовое чутье, / Умение жадно за жизнь держаться / И отдавать, когда нужно, ее» [10, с. 351]. Мужество и мужественность самой эпохи заражают людей общей идеей и в императивном порядке диктуют необходимость следовать ей. А иначе нельзя. Не выживешь. Не защитишь. Не спасешь. Мужество становится аксиологической доминантой жизни всех от мала до велика. У К. М. Симонова эта мысль с особой простотой и в то же время глубиной раскрывается в единственном его лиро-эпическом произведении военного времени - в «Сыне артиллериста» (1941).

\section{Мотивный комплекс в поэме К. М. Симонова «Сын артиллериста» и ее жанровое своеобразие как средства реализации концепта «мужество»}

3. И. Макарова называет «Сына артиллериста» «великолепным образцом баллады военных лет» [7, с. 19], обнаруживая связь произведения К. М. Симонова с балладами прошлого не столько в сюжетной основе (один эпизод) и в традиционных элементах (троекратный повтор, тема неизбежности судьбы), сколько в «романтически-приподнятом плане» [Там же]. В то же время исследователь отмечает пограничность жанра «Сына артиллериста», приближенность баллады к поэме, которая в годы войны «приобрела новые свойства и оттенки» [Там же, с. 23]. Жанр баллады в период Великой Отечественной войны должен был существенно трансформироваться, поскольку «литература социального выбора нуждалась в героико-трагической семантике баллады» [6, с. 18]. Указывая как на одну из особенностей авторского представления событий и героев в «Сыне артиллериста»- на «интерес к национально-историческим истокам подвига, его морально-психологической составляющей», И. Ф. Герасимова также относит данное произведение к «фронтовым балладам» [3, с. 13], при этом в развитии жанра баллады в военные годы усматривая возрастание роли авторской субъективности, усиление лирического начала и «эмоционального фактора, призванного напрямую воздействовать на массовое народное сознание» [Там же, с. 14]. Иными словами, симоновское произведение, сочетая в себе жанровые признаки баллады с углубленным лирическим началом, представляет трагически-героические события в обостренноличностном преломлении, при этом сохраняя эффект отстраненности повествователя. Именно так, как о чем-то совершенно естественном и не вызывающем ни малейшего сомнения, можно было говорить о мужестве, не уходя в высокую патетику. 
Известно, что баллада строится на антитезе, и в «Сыне артиллериста» эта балладная черта проявляется в системе, состоящей из нескольких концептуально значимых оппозиций: оппозиция времени (тогда - сейчас, до - после), жизнь и смерть, слабость и стойкость, ощущение счастья и невозможность его испытать, опытность и ученичество и др.

Показательно, что концепт «мужество» эксплицитно не воплощается в этом произведении через оппозицию мужество - не-мужество / страх / трусость. Она имплицитно достраивается читателем под ненавязчивым воздействием расставленных автором ориентиров. Идея мужества, находящая воплощение в образах мужественных защитников Родины, Отчизны, готовых на самопожертвование ради спасения русской земли, реализуется также в системе мотивов, что будет показано далее.

\section{Своеобразие мотивного и образного слоев концепта «мужество» в поэме К. М. Симонова «Сын артиллериста»}

Экспозиция «Сына артиллериста» выдержана в подчеркнуто легких, балагурно-разговорных тонах, «в стилистике бывальщины и сказовых интонаций» [1, с. 157]. Но за этой легкостью - героическое прошлое и крепкая дружба двух боевых товарищей, майоров Петрова и Деева, их взаимопомощь и взаимоподдержка, воспитание Леньки, сына Петрова, для которого Деев становится «вторым отцом». «В повествовании выделяются важные для народного сознания константы дружбы (товарищества), отцы и дети...» [Там же]. Мотивы дружбы и братства, характерные, пожалуй, для всей русской военной лирики, пронизывают все произведение К. М. Симонова и оказываются сопряженными с мотивами верности, чести и долга, преемственности поколений. При этом объединяющим все эти мотивы является, на наш взгляд, мотив мужества: мужество как норма жизни, как знак героического прошлого и героического настоящего, мужество как потребность и необходимость.

Три героя (символическое сходство с тремя богатырями) - три жизни - три варианта проявления мужества в служении стране и народу. И если о мужестве старшего Петрова написали в газете, а о его героической гибели стало известно многим - майору Дееву «кто-то сказал» об этом, то мужество самого Деева по воле автора, может, не столь «громкое», должно было проявиться не только в том, чтобы сражаться самому («В сто раз ему было б легче, / Если бы шел он сам» [10, с. 493]), но и в том, чтобы отправить на практически невыполнимое, смертельно опасное задание человека, которому он заменил отца, фактически пожертвовав им ради спасения боевых товарищей: «Идешь на такое дело, / Что трудно прийти назад. / Как командир, тебя я / Туда посылать не рад. // Но как отец... / ... // - Так вот, как отец, раз вышло / На жизнь и смерть воевать, / Отцовский мой долг и право / Сыном своим рисковать. // Раньше других я должен / Сына вперед послать» [Там же, с. 492-493].

Мужество самого младшего из героев - в понимании и исполнении долга, в готовности к самопожертвованию. И это мужество - результат воспитания, некий итог нравственного совершенствования, этапы которого лишь пунктирно обозначены по ходу развития сюжета. Однако, на наш взгляд, на них следует остановиться подробнее.

Жизнь Леньки проходит перед глазами читателя как в ускоренном фильме: вот он совсем мальчишка, который неуверенно держится на лошади, порой «взять не сможет барьер, / Свалится и захнычет», но рядом оказывается поддерживающее слово «второго отца»- пословица, рефреном звучащая в произведении: «Держись, мой мальчик: на свете // Два раза не умирать» [Там же, с. 490]. «Удаль воинов Древней Руси прослеживается в лейтмотиве поэмы, которым и стала эта пословица» [1, с. 157]. Отметим, что в русском языке пословицы и поговорки о мудрости жизни, построенные на отрицании, встречаются довольно часто. Вспомним: жизнь пройти - не поле перейти, сколько ни ликовать, а смерти не миновать, два века не проживешь, две молодости не перейдешь. Среди них есть и такая, которая, на наш взгляд, вполне могла бы выразить путь становления мужества и удали русского солдата, офицера: Кто смерти не боится - не велика птица, а вот кто жизнь полюбил - тот страх загубил. И в этом отношении интересно отметить одну, на первый взгляд, фактографическую неточность в тексте: майоры Петров и Деев артиллеристы, не кавалеристы, а потому слова Деева, обращенные к Леньке: «Сыну артиллериста / Пора к коню привыкать!»- есть не что иное, как знак необходимости научить преодолевать трудности, неважно, в чем они заключаются, научить любить жизнь, даже если она приносит боль и страдания. И это поможет преодолеть смерть. Становление мужества - преодоление себя и внешних обстоятельств - урок, усвоенный Петровым-младшим, впитавшим в себя поговорку «второго отца»: «Ничто нас в жизни не может // Вышибить из седла!» [10, с. 490].

Эти же слова Ленька, раненный в голову, скажет ему в ответ, когда будет уезжать в госпиталь: таких действительно «ничто не может вышибить из седла» - ни в прямом, ни в фигуральном смысле.

Своего рода этапами возмужания Леньки, выразившимися в портретной характеристике героя, могут быть названы встречи с майором Деевым по прошествии определенного времени. По ходу развития сюжета Ленька встречается со «вторым отцом» через 10 лет разлуки, уже после гибели родного отца, майора Петрова. Эпизод встречи майора Деева и его выросшего подопечного Леньки - лейтенанта Петрова - вводит в произведение традиционный мотив узнавания, сопряженный с мотивом воспоминания, и рождает ряд героикоромантических ассоциаций: склонившийся над картой умудренный опытом командир, чадящие свечи в полумраке землянки и будто осветивший ее своей молодостью и богатырской силой военный. Психологическая напряженность момента и нахлынувшие на героев воспоминания выражены по-мужски немногословно, но в высокой степени точно и осязаемо: «Жаль, до такого счастья / Отцу не пришлось дожить. // У Леньки в глазах блеснула / Непрошеная слеза. / Он, скрипнув зубами, молча / Отер рукавом глаза» [Там же, с. 491]. 
С этого момента и до конца развития действия Деев и Ленька вместе, плечом к плечу, защищают родную землю. Однако в сюжете появляется еще один эпизод «узнавания». Знаковая встреча майора Деева и Петрова-младшего произошла после боя, увенчавшегося победой благодаря мужеству Леньки. Сравним два этих момента, они весьма показательны. При первой встрече после долгой разлуки: «Вошел высокий военный, / Косая сажень в плечах. // В первые две минуты / Майор его не узнал. / Лишь басок лейтенанта / О чем-то напоминал. // ... / Все те же детские губы, / Тот же курносый нос. // А что усы - так ведь это / Сбрить! - и весь разговор» [Там же]. В портретной характеристике сохраняется детскость и подчеркивается, что «показатель взрослости» - усы - легко может быть устранен, это не главное. Обратим внимание: майор не знает, кто перед ним, но узнает Леньку через две минуты. Во втором же эпизоде все иначе: «Когда размотали повязку, / Что наспех он завязал, / Майор поглядел на Леньку / И вдруг его не узнал: // Был он как будто прежний, / Спокойный и молодой, / Все те же глаза мальчишки, / Но только... совсем седой» [Там же, с. 495] (курсив наш. Чжан Вэй). Детскость - характеристика, уже фигурировавшая в первом портрете, но здесь она касается глаз (глаза - зеркало души). За один бой как будто прошла вся жизнь, и это жизнь мужественного человека, не потерявшего спокойствия, по-детски продолжающего любить жизнь и тем самым противостоять смерти. Мотив узнавания помогает атрибутировать этапы «взросления» мужества в герое.

\section{Воплощение концепта «мужество» через композиционные особенности поэмы «Сын артиллериста»}

Кинематографичность в «Сыне артиллериста», не только способствующая идейно значимому «сжатию» и «растягиванию» в нем хронотопа, позволяет с легкостью переключать планы изображения и менять географически отдаленные объекты. Однако этот же прием в совокупности с некоторыми другими помогает автору объединять события, факты, объекты, временные и пространственные точки общей, связующей идеей.

В экспозиционной части географическая противопоставленность Севера и Юга, подчеркнутая разделенность многими километрами огромной страны между тем воспринимаются, напротив, как неразрывное единство за счет композиционного кольца и лексического повтора: Деев дрался на Севере - На Юге дрался Петров, - главное - единство мысленное, духовное родство, незыблемые узы дружбы, мужество. В какой-то момент начинает казаться, что Деев и Петров - это уже не конкретные люди, а обобщенно-собирательный образ мужественного защитника, готового драться, независимо от его местоположения, за будущее страны. Говоря о героях и сюжетах произведений К. М. Симонова, Д. В. Абашева отмечает, что они «имеют универсальное значение для понимания “тихого”, без бравурности и широкой огласки, типичного в своей повторяемости подвига народа» [1, с. 159].

Ситуация географической противопоставленности повторится при описании выполнения младшим Петровым труднейшего боевого задания. Между героями - линия фронта и скалы, но тем более явственно передается внутреннее единство Леньки и майора Деева, уверенность второго в то, что названый сын его не подведет и выполнит свой долг до конца. Тончайшие оттенки чувств, испытываемых героями, передаются в эпизоде последнего разговора между ними перед заданием через ряд почти незаметных деталей: двойственность роли Деева, командира и отца, обусловливает эмоционально-экспрессивную напряженность ситуации, которую читатель воспринимает глубоко личностно: умение забыть о своих чувствах, сменить роль отца на роль командира и наоборот, если этого требует дело, сродни мужеству.

В кульминационных строфах «Сына артиллериста» действия Петрова-младшего мы видим как будто попеременно глазами майора Деева - командира и глазами Деева - «второго отца», иногда точки зрения сливаются - невозможно разобраться, где эмоции командира, а где - отца. Гипотетические картины, рождающиеся в сознании Деева, сменяются реальными планами, в которых глубокое волнение, как и в предыдущих эпизодах, передается за счет деталей: раздражение на луну, яркий свет которой может сделать заметным движение Леньки в тылу врага, напряженное слежение за идущим временем, незримое присутствие рядом с Ленькой («Сейчас, наверно, / Прошел он через посты. / Час... Сейчас он добрался / К подножию высоты. // Два... Он теперь, должно быть, / Ползет на самый хребет...» [10, с. 493]), вышагивание «как маятник» на протяжении всей ночи, собственные расчеты артиллерийских ударов... Мужество опытного бойца Деева передается Леньке на расстоянии, но тот и сам проникнут идеей мужества, с детства привитой ему отцами-героями (преемственность поколений). И потому не случайно в момент наивысшего напряжения, в момент, казалось бы, неминуемой гибели слова и Деева, и Леньки максимально созвучны, как будто вторят друг другу, ср.: «Я верю, свои снаряды / Не могут тронуть меня» - «Ты слышишь меня, я верю: / Смертью таких не взять» (курсив наш. - Чжан Вэй). Верить в жизнь, когда вокруг смерть, - это, на наш взгляд, тоже мужество. В совокупности с проходящей в произведении рефреном поговоркой Деева, а потом и Леньки эти слова утверждают отношение к смерти как к естественному ходу событий, как к неизбежности, но при этом проводят мысль о необходимости сохранить честь и достоинство, не «выпасть из седла». Метафорически образное представление идеи необходимости идти до конца и мужественно выполнять свой долг до последнего вздоха, и тогда смерть не страшна.

Трудно согласиться с высказанной И. Ф. Герасимовой мыслью о том, что в «Сыне артиллериста» К. М. Симонов поднимает проблему истинного и ложного гуманизма, которая, в частности, по мнению автора, проявляется в вынужденном решении Деева отправить Леньку на верную гибель [3, с. 14]. Нет, на наш взгляд, это действительно невероятно трудное решение по воле поэта воплощает идею не истинного и ложного гуманизма, но истинного и ложного героизма и мужества. На войне нет места избирательным псевдогероизму и псевдомужеству. Мужество императивно именно по причине того, что оно является внутренней потребностью личности. Иначе поступить нельзя. Невозможно. 
Заключительные строфы произведения выводят сюжет на уровень широкого обобщения, образы укрупняются, становятся максимально типизированными, но при этом не менее выразительными и глубоко психологически обусловленными. Повторяемость ситуации, подчеркнутая словами так же / всё так же и сходными по смыслу предложениями с близкой структурой (ср.: «шагая как маятник, / Глаз майор не смыкал» - «волнуясь, / Командир по землянке ходил»), создает ощущение ее естественности и правильности, не героики, а нормы, поскольку она отражает «константы народного сознания» [1, с. 159], идеал мужества.

\section{Заключение}

В результате проведенного исследования мы пришли к следующим выводам: идеал мужества, равно как и сама идея мужества, в произведении К. М. Симонова «Сын артиллериста» играют большую роль в организации концептуального пространства текста. Художественный концепт «мужество», как одна из «констант народного сознания», становится аксиологической доминантой художественного мира автора, репрезентирует нравственно-этическую концепцию жизни и смерти, реализуется на уровне мотивного комплекса, передается через образы героев и всю ассоциативно-образную систему, при этом идея мужества реализуется прежде всего как нравственный императив. Перспективы дальнейшего исследования нам видятся в изучении концепта «мужество» в других произведениях К. М. Симонова в соотнесении с иными концептами индивидуально-авторской картины мира писателя, а также в сравнительно-сопоставительном изучении особенностей репрезентации этого концепта в творчестве поэтов - представителей различных поколений с целью выявления его динамики.

\section{Источники | References}

1. Абашева Д. В. Константы народного сознания в поэме К. М. Симонова «Сын артиллериста» // Отечественная словесность о войне. Проблема национального сознания: к 70-летию Победы в Великой Отечественной войне: материалы ХХ Шешуковских чтений / под ред. Л. А. Трубиной. М.: МПГУ, 2015. С. 154-160.

2. Базылова Л. А. Концепт ДОМ в индивидуально-авторской картине мира А. Ахматовой // Вестник Челябинского государственного педагогического университета. 2009. № 6. С. 202-209.

3. Герасимова И. Ф. Человек и время: поэзия К. М. Симонова периода Великой Отечественной войны в контексте литературной эпохи: дисс. ... к. филол. н. М., 2008. 189 с.

4. Голованова Е. И. «Война» в национальном сознании: концептуальные доминанты русского песенного дискурса // Лингвистика XXI века: сборник научных статей: к 65-летнему юбилею проф. В. А. Масловой / соред. В. В. Колесов, М. В. Пименова, В. И. Теркулов. К.: Изд. дом Д. Бураго, 2013. С. 109-117.

5. Голованова Е. И., Потапчук М. А. «За себя и за того парня...»: ментальные проекции Великой Отечественной войны в крылатых словах и выражениях // Вестник Челябинского государственного университета. 2012. № 13 (267). Филология. Искусствоведение. Вып. 65. С. 29-32.

6. Дашевская О. А. Поэзия Великой Отечественной войны: эстетика, проблематика, жанрово-стилевые тенденции: учебно-методическое пособие для студентов-филологов. Томск: Изд-во Томского гос. ун-та, 2016. 136 c.

7. Макарова 3. И. Русская поэма в годы Великой Отечественной войны: дисс. ... д. филол. н. Элиста, 1998. 403 с.

8. Пономарева Т. А. Концепт «Родина» в лирике военных лет Д. Б. Кедрина // Отечественная словесность о войне. Проблема национального сознания: к 70-летию Победы в Великой Отечественной войне: материалы ХХ Шешуковских чтений / под ред. Л. А. Трубиной. М.: МПГУ, 2015. С. 147-154.

9. Рогова К. А. Константин Симонов. К столетию со дня рождения // Мир русского слова. 2015. № 4. С. $117-120$.

10. Симонов К. М. Собрание сочинений: в 10-ти т. / вступ. ст. Л. Лазарева; коммент. А. Александровой. М.: Худож. лит., 1979. Т. 1. Стихотворения. Поэмы. Вольные переводы. 670 с.

\section{Информация об авторах | Author information}

RU Чжан Вэй

${ }^{1}$ Московский педагогический государственный университет

EN Zhang Wei ${ }^{1}$

${ }^{1}$ Moscow Pedagogical State University

${ }^{1} 1548322072 @ q q . c o m$

\section{Информация о статье | About this article}

Дата поступления рукописи (received): 17.07.2021; опубликовано (published): 15.09.2021.

Ключевые слова (keywords): художественный концепт; концепт «мужество»; поэзия Великой Отечественной войны; К. М. Симонов; Сын артиллериста; literary concept; concept “courage”; poetry of the Great Patriotic War; K. M. Simonov; The Artilleryman’s Son. 